\title{
BIOINDICATORS AS A TOOL IN ENVIRONMENTAL IMPACT ASSESSMENT: CYANOBACTERIA AS A SENTINEL OF POLLUTION
}

\author{
ROBERTA TETA, ${ }^{1}$ GERMANA ESPOSITO,${ }^{1}$ MARCO CASAZZA, ${ }^{2}$ CHRISTOPHER J. ZAPPA, ${ }^{3,2}$ \\ THEODORE A. ENDRENY, ${ }^{4}$ ALFONSO MANGONI, ${ }^{1}$ VALERIA COSTANTINO ${ }^{1} \&$ \\ MASSIMILIANO LEGA ${ }^{2}$ \\ ${ }^{1}$ Department of Pharmacy, University of Naples "Federico II", Naples, Italy. \\ ${ }^{2}$ Department of Engineering, University of Naples "Parthenope", Naples, Italy. \\ ${ }^{3}$ Lamont-Doherty Earth Observatory, Columbia University, Palisades, New York, USA. \\ ${ }^{4}$ College of Environmental Science and Forestry, State University of New York, Syracuse, USA.
}

\begin{abstract}
The correlation between stressors and bioindicators can provide evidence of environmental status both as an indication and monitoring tool, and in the identification of the pollutant source. Cyanobacteria possess several hallmark traits of good bioindicators: physiological tolerances or ecological ranges of specific cyanobacterial species can differ depending on taxon-specific cellular requirements. In certain conditions cyanobacteria can form extensive blooms; this phenomenon arising from excessive nutrient input is usually of anthropogenic origin, resulting from a myriad of sources including point sources from municipal and industrial discharges, and non-point sources from agricultural run-off.

This work is integrated with the activities carried out within a wider research project aimed at (a) characterizing the role of cyanobacteria as a good bioindicator of coastal water quality, (b) advancing a hierarchical monitoring approach using space-borne remote sensing to in-situ sampling and laboratory microscope analysis of cyanobacteria, (c) reporting on the taxonomic analysis of the cyanobacterial community in the coastal waters of Campania region in southern Italy, and (d) exploring the relationship of cyanobacteria with the terrestrial river basins draining to the coast.

In this study, the occurrence of specific cyanobacteria species in extremely polluted environment has been investigated. Specifically, the target point has been selected based on the discharge from the wastewater treatment plant in Cuma, Campania region (Italy). These analyses can support environmental impact studies by governmental officials regarding aquatic pollution problems e.g. determining the effectiveness of wastewater plants in preventing eutrophication impacts within specific coastal areas. Keywords: bioindicators, cyanobacteria, cyanotoxin, early detection, environmental monitoring, impact assessment.
\end{abstract}

\section{INTRODUCTION}

Considering the increase in spatial extent, frequency, and magnitude of disturbances to the environment, and the rapid development of new stressors, including those arising from climate changes, there is an urgent need of monitoring programs able to track and help manage their impact [1]. Monitoring programs based on chemical and physical analytical methods provide direct measurements of different environmental quality parameters at that particular point (i.e. water column) and period of time. If the frequency of sampling is limited, or hampered by different factors (i.e. weather conditions, safety reasons), important information can be lost. Moreover, analytical data may be limited to very narrow indications on the overall condition of the environment, restricted to a few representative measures (i.e. temperature, salinity, nutrients, metals). Therefore, they are not sufficient to represent a more holistic health of the environment. To address this issue, bioindicators are used to capture the integrated chemical and physical disturbances. Using living organisms such as plants, planktons, animals, and microbes, that interact with the environment (therefore with the stressors) and respond accordingly, brings many benefits. 
Bioindication and biomonitoring are powerful tools for observing the impact of external factors on ecosystems and their development over time and space [2]. They belong to the generic biological monitoring, comprising biomarkers and biosensors [3]. Biomarkers are measurable biological parameters, whose levels vary in consequence with environmental changes, while biosensors, such as the bioluminescent bacteria, produce a signal in proportion to the concentration of a defined substance [4]. Bioindication offers numerous advantages over not only the chemical/physical analytical methods but also with respect to biomarkers and biosensors. This technique provides the capability to assess the cumulative impacts of both pollutants and habitat alterations. Moreover, it allows a detailed and reliable coverage of the territory with relatively low costs [5] and less time-consumption. Depending only on the life span of the living organism, and regardless of sampling frequency, sporadic pulses of pollutants are captured by bioindicators. Further, bioindicators are sensitive to low concentrations of pollutants, capturing diluted seepage and other inflows perhaps missed by traditional sampling.

This work is integrated with the activities carried out within a wider research project, aimed at: (a) characterizing the role of cyanobacteria as a good bioindicator of coastal water quality; (b) advancing a hierarchical monitoring approach using space-borne remote sensing to in-situ sampling and laboratory microscope analysis of cyanobacteria; (c) reporting on the taxonomic analysis on the cyanobacterial community in the coastal waters of Campania region in southern Italy; (d) exploring the relationship of cyanobacteria with the terrestrial river basins draining to the coast [6].

There is not a clear-cut distinction between bioindicators and biomonitors. The term 'bioindicator' refers to qualitative biotic responses to environmental stress, while 'biomonitors' to quantitative biotic responses. An effective bioindicator is widespread, can be easily identified and sampled, has low mobility and a long-life cycle, and is not dangerous to handle. Based on these criteria, cyanobacteria are good bioindicators of water quality. Cyanobacteria are known for their ability to accumulate in waters surface forming blue-green foams called "blooms" and in some conditions to produce toxins (namely cyanotoxins) [7]. Cyanobacteria are well suited to water quality assessment because of their nutrient needs, rapid reproduction rate, and their life cycle.

\section{RESULTS AND DISCUSSION}

Cyanobacteria are ubiquitous microorganisms, able to live in any ecological niches; being photosynthetic, the main factors affecting their growth are nutrients and light availabilities [8]. The nutrient enrichment of many waterbodies (eutrophication) due to anthropogenic pressure, domestic and industrial effluents, wastewaters, and agriculture activities (pesticides and fertilizers) has led to the proliferation of cyanobacteria throughout the world.

The response of cyanobacteria to environmental stressors varies according to the different degree of contamination or degradation and can differ depending on taxon-specific cellular requirements [9]. Several species of Oscillatoria have been described as bioindicators of organically polluted waters, being tolerant to high trophic levels, while other species, such as those belonging to Calothrix and Tolypotrix genera, were commonly associated with clean waters. The morphology of cyanobacteria comprising unicellular, colonial, and multicellular filamentous forms may provide useful insights to the nutrient status of the waters. For example, the presence of heterocysts in a filament is an indication that the organism is growing in an environment deficient in combined nitrogen $\left(\mathrm{NO}_{3}{ }^{-}, \mathrm{NO}_{2}^{-}, \mathrm{NH}_{4}{ }^{+}\right)$relatively to other nutrients. Similarly, cyanobacteria, such as Phormidium, can accumulate polyphosphate granules in P-rich environment. 


\subsection{Evidences of cyanobacteria in polluted waters}

Our previous studies [10] revealed the presence of cyanobacteria along the coastal waters of Campania region in Italy, a territory plagued by several criticalities due to illicit discharges and improper management of wastewater treatment plants. In this study, the occurrence of specific cyanobacteria species in extremely polluted environment has been investigated, focusing on the discharge from the wastewater treatment plant in Cuma as a case study (see Fig. 1). In addition to flaws in the operation of the wastewater plant, the study site is impacted also by discharges from a huge residential area [11].

The evidence of this critical condition has been reported by the Environmental Protection Agency of Campania region in Italy (ARPAC) in the Recreational Water Quality assessment document. Follows a table (Table 1) with the results of 2017 summer season for the study site. Results (Fig. 2) revealed high levels of microbial load and eutrophication in the study area, thus likely stimulating the proliferation of cyanobacteria.

The extension of the polluted area has been defined using the MUM $^{3}$ framework [12] following an approach that integrates satellite analyses [13, 14, 15] and in situ sampling and measurements [16]. Proliferation of photosynthetic cells is reflected in the increase of the levels of Chl-a; therefore, Chl-a and carotenoid pigments are routinely used to assess the extension of a cyanobacterial/algal bloom.

Figure 3 is the Chl-a map of the coastal area obtained through World View (NASA tool) and selecting Acqua/Terra MODIS data layer. It shows the output source of the Cuma treated wastewater discharge (man-made channel at study site B) and the nearby coastal region to the north to be increased in Chl-a relative to the surrounding waters $[17,18]$.

Microscopic observation of water sampled on the study site revealed the presence of cyanobacteria as shown in Fig. 4. A prevalence of Anabaena species could be recognized in the examined sample showing a few heterocystis. Higher eutrophication levels and high turbidity caused a reduction in available light, and as a consequence less energy was available for the energy-consuming process of nitrogen fixation. Anabaena is a species that produces toxin. Our next steps will aim to identify the toxins produced.

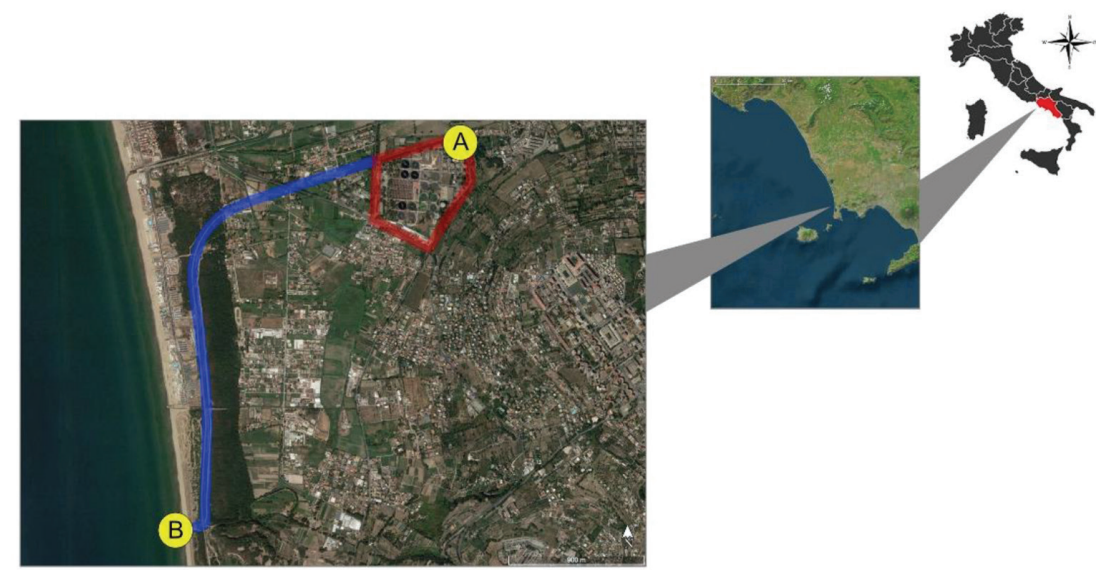

Figure 1: Study site of Cuma wastewater treatment plan (Campania region - Italy); A. Cuma wastewater treatment plan area (red). B. Input of treated waters to the sea through a man-made channel (blue). 
Table 1: 2017 recreational waters quality assessment performed by ARPAC on Cuma study site (sampling code: IT015063060005); R: Routine sampling point, PS: study point, DEL: special activity developed to detect limits of impacted area; *(UFC o MPN /100 ml, limit 500).

\begin{tabular}{lcccccc}
\hline Date & Hour & Type & Air temp. & Water temp. & E. faecalis ${ }^{*}$ & E. coli* $^{*}$ \\
\hline $2017-12-04$ & $11: 40$ & $\underline{R}$ & 21 & 18,5 & 10 & 20 \\
$2017-12-04$ & $11: 47$ & $\underline{P S}$ & 21 & 17,8 & 10 & 10 \\
$2017-22-05$ & $12: 40$ & $\underline{P S}$ & 26 & 21 & 2005 & 591 \\
$2017-22-05$ & $12: 50$ & $\underline{R}$ & 26 & 21 & 1298 & 324 \\
$2017-19-06$ & $11: 34$ & $\underline{R}$ & 27 & 23,6 & 10 & 10 \\
$2017-19-06$ & $11: 40$ & $\underline{P S}$ & 27 & 23,6 & 10 & 42 \\
$2017-17-07$ & $12: 10$ & $\underline{R}$ & 25,9 & 25,7 & 10 & 10 \\
$2017-17-07$ & $12: 18$ & $\underline{P S}$ & 26,3 & 25,2 & 10 & 10 \\
$2017-10-08$ & $11: 40$ & $\underline{P S}$ & 32 & 29,5 & 87 & 20 \\
$2017-10-08$ & $11: 50$ & $\underline{R}$ & 32 & 29,5 & 2005 & 2005 \\
$2017-16-08$ & $10: 12$ & $\underline{D E L 2}$ & 26,3 & 27,3 & 10 & 10 \\
$2017-16-08$ & $10: 15$ & $\underline{S}$ & 26,3 & 37,3 & 10 & 10 \\
$2017-16-08$ & $10: 17$ & $D E L 1$ & 26,3 & 27,4 & 10 & 31 \\
$2017-08-09$ & $15: 04$ & $\underline{P S}$ & 26,2 & 25,8 & 344 & 624 \\
$2017-08-09$ & $15: 09$ & $\underline{R}$ & 26,2 & 25,8 & 384 & 659 \\
\hline
\end{tabular}
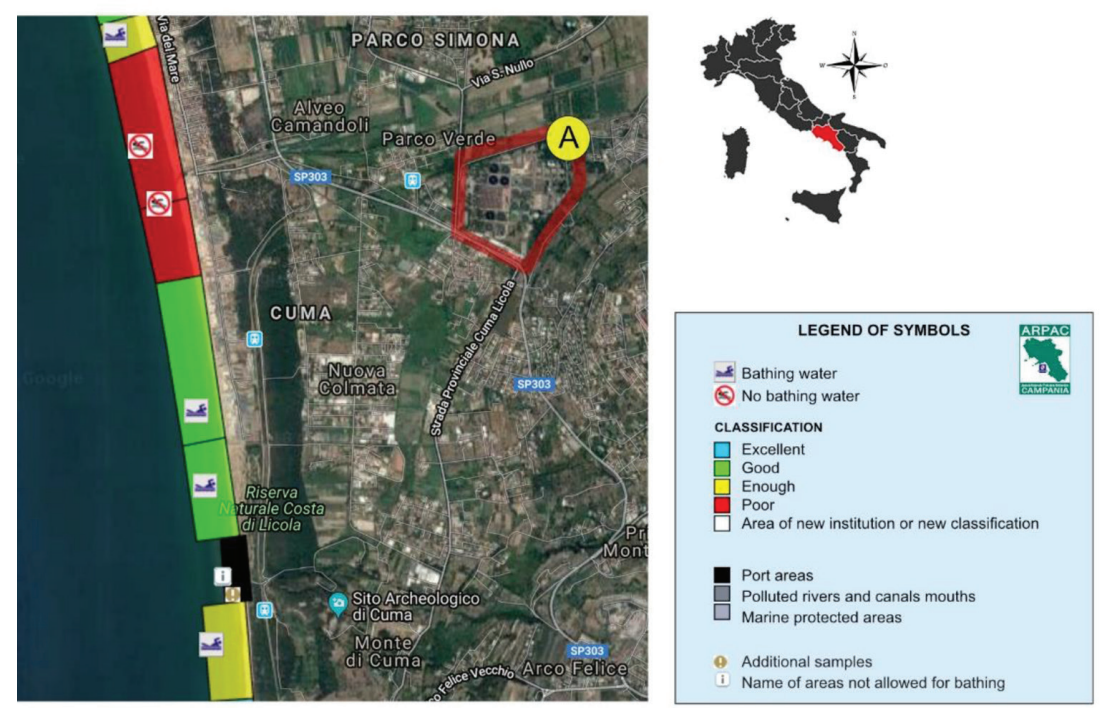

Figure 2: ARPAC recreational water quality map. 

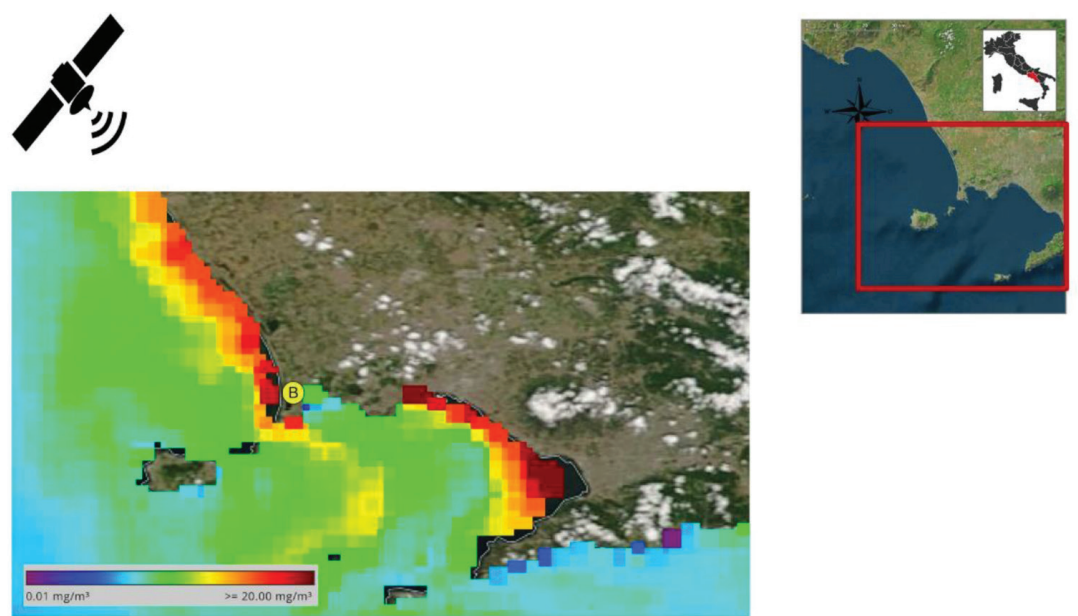

Figure 3: Chl- $a$ satellite analysis on the study site B (Terra/Aqua MODIS).
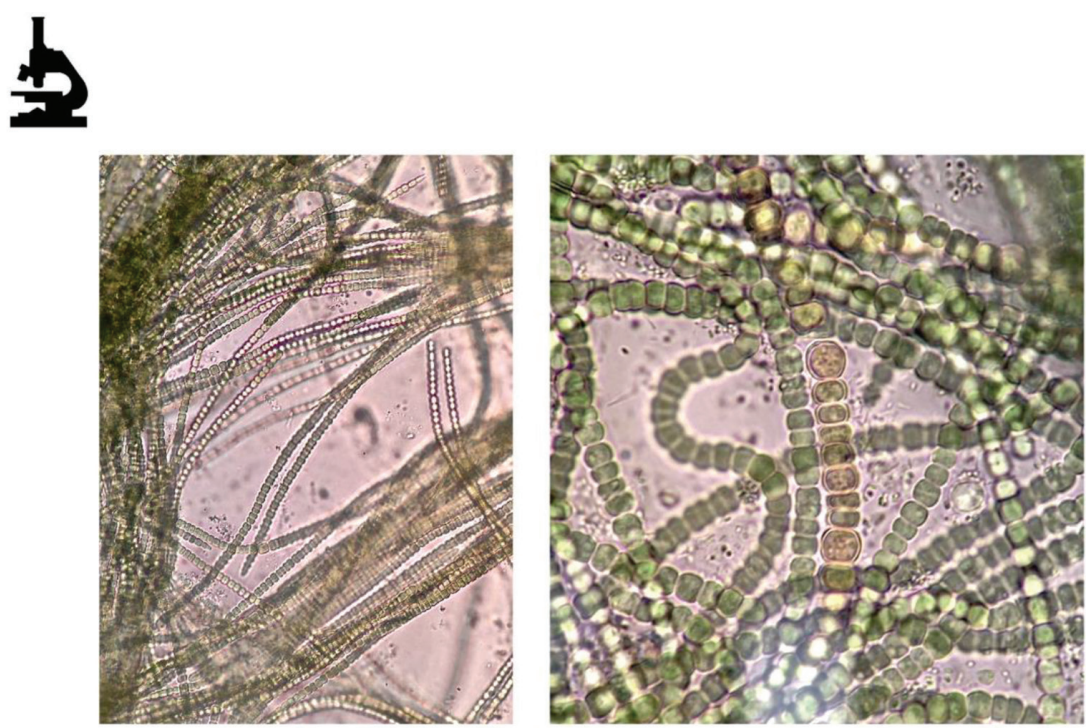

Figure 4: Microscope observations of Cuma wastewater treatment plant sample.

\section{MATERIALS AND METHODS}

\subsection{Satellite analyses}

Chlorophyll and carotenoid pigments contained within photosynthetic cells (algae, cyanobacteria etc.) are routinely used to assess algal biomass and phylogenetic composition and distribution in aquatic ecosystems. The chlorophyll-a (Chl-a) map of the coastal area of Campania coasts was obtained from MODerate Image Spectroradiometer (MODIS) sensor, mounted on Terra and Aqua satellite platforms. The operational algorithm allowed the Chl-a 
quantification expressed in $\mathrm{mg} / \mathrm{m}^{3}$ in water bodies. The spatial resolution (pixel size) is $1 \mathrm{~km}$ $\mathrm{x} 1 \mathrm{~km}$, while the temporal resolution is daily.

\subsection{In situ sampling and measurements}

Samples were collected at the study site B (geographic coordinates: $40.850405 \mathrm{~N}, 14.046552 \mathrm{E}$ ) in the summer 2017 (dates: 07/17/17, 08/10/17, 09/07/17), when the highest levels of Chl-a were detected according to ARPAC recreational waters quality assessment. Collected water sample was analyzed with an optical microscope combined with an OMAX 18 MP CMOS cooled camera. All analysis and measurements were performed digitally using specialized scientific software (ToupView). This allowed the qualitative detection of cyanobacteria.

\section{CONCLUDING REMARKS}

Bioindication provides information on the response of living organisms to the integrated effects of environmental contaminants, which cannot be determined by direct analytical measurements. Compared to chemical and physical measures of environmental quality, bioindicators are capable of capturing cumulative impacts of multiple pollutants and habitat changes, in an early stage and over time. Cyanobacteria are good bioindicators of water quality, and providing rapid response detection could be considered desirable as an 'early warning' indicator of change. Only the assessment of the presence, abundance and performance of living organisms in the field can give insights on the impact of environmental stress on the composition and health of the ecosystem.

\section{ACKNOWLEDGEMENTS}

The data presented in this work derive from the project 'Attività pilota di Monitoraggio di Cianobatteri nella fascia costiera della regione Campania', funded by the 'Centro di Riferimento Regionale per la Sicurezza Sanitaria del Pescato ( CRiSSaP)' and performed in cooperation with the Agency for the Environmental Protection of Campania region in Italy (ARPAC), Istituto Zooprofilattico Sperimentale del Mezzogiorno/Osservatorio Regionale per la Sicurezza Alimentare - IZSM/ORSA, University of Naples "Federico II" (Department of Pharmacy, ref. prof. V. Costantino and Department of Veterinary Medicine and Animal Production, ref. prof. A. Anastasio), University of Naples "Parthenope" (Department of Engineering, ref. prof. M. Lega). This is Lamont-Doherty Earth Observatory contribution number 8244. This project was supported in part by the University of Naples "Parthenope" (Italy) under 'Bando di sostegno alla ricerca individuale'. Finally, the authors are grateful for the support from the United States and Italy Fulbright Commission, who have facilitated this collaboration.

\section{REFERENCES}

[1] Cooper, T.F., Gilmour, J.P. \& Fabricius, K.E., Bioindicators of changes in water quality on coral reefs: Review and recommendations for monitoring programmes. Coral Reefs, 28(3), pp. 589-606, 2009. https://doi.org/10.1007/s00338-009-0512-x

[2] Holt, E.A. \& Miller, S.W., Bioindicators: using organisms to measure environmental impacts. Nature Education Knowledge, 3(10), p. 8, 2010.

[3] Markert, B., Definitions and principles for bioindication and biomonitoring of trace metals in the environment. Journal of Trace Elements in Medicine and Biology, 21(SUPPL. 1), pp. 77-82, 2007. https://doi.org/10.1016/j.jtemb.2007.09.015 
[4] Britstein, M., Devescovi, G., Handley, K.M., Malik, A., Haber, M., Saurav, K., Teta, R., Costantino, V., Burgsdorf, I., Gilbert, J.A., Sher, N., Venturi, V. \& Steindler, L., A new $\mathrm{N}$-Acyl homoserine lactone synthase in an uncultured symbiont of the red sea sponge Theonella swinhoei. Applied and Environmental Microbiology, 82(4), pp. 1274-1285, 2016. https://doi.org/10.1128/AEM.03111-15

[5] Girotti, S., Maiolini, E., Bolelli, L., Ghini, S., Ferri, E., Barile, N. \& Medvedeva, S., Analytical techniques and bioindicators in environmental control: honeybees, mussels, bioluminescent bacteria: rapid immunoassays for pesticide detection. Soil Chemical Pollution, Risk Assessment, Remediation and Security, pp. 327-347, 2008. https://doi.org/http://dx.doi.org/10.1007/978-1-4020-8257-3_29

[6] Lega, M. \& Endreny, T., Quantifying the environmental impact of pollutant plumes from coastal rivers with remote sensing and river basin modelling. International Journal of Sustainable Development and Planning, 11(5), pp. 651-662, 2016. https://doi.org/10.2495/sdp-v11-n5-651-662

[7] Teta, R., Della Sala, G., Glukhov, E., Gerwick, L., Gerwick, W.H., Mangoni, A. \& Costantino, V., Combined LC-MS/MS and Molecular Networking Approach Reveals New Cyanotoxins from the 2014 Cyanobacterial Bloom in Green Lake, Seattle. Environmental Science and Technology, 49(24), pp. 14301-14310, 2015. https://doi.org/10.1021/acs.est.5b04415

[8] Teta, R., Della Sala, G., Mangoni, A., Lega, M. \& Costantino, V., Tracing cyanobacterial blooms to assess the impact of wastewaters discharges on coastal areas and lakes. International Journal of Sustainable Development and Planning, 11(5), pp. 804-811, 2016. https://doi.org/10.2495/SDP-V11-N5-804-811

[9] Mateo, P., Leganés, F., Perona, E., Loza, V. \& Fernández-Piñas, F., Cyanobacteria as bioindicators and bioreporters of environmental analysis in aquatic ecosystems. Biodiversity and Conservation, 24(4), pp. 909-948, 2015. https://doi.org/10.1007/s10531-015-0903-y

[10] Teta, R., Romano, V., Della Sala, G., Picchio, S., De Sterlich, C., Mangoni, A., De Sterlich, C., Mangoni, A., Di Tullio, G., Costantino, V. \& Lega, M., Cyanobacteria as indicators of water quality in Campania coasts, Italy: A monitoring strategy combining remote/proximal sensing and in situ data. Environmental Research Letters, 12(2), 2017. https://doi.org/10.1088/1748-9326/aa5649

[11] Errico, A., Angelino, C.V., Cicala, L., Podobinski, D.P., Persechino, G., Ferrara, C., Lega, M., Vallario, A., Parente, C., Masi, G., Gaetano, R., Scarpa, G., Amitrano, D., Ruello, G., Verdoliva, L. \& Poggi, G., SAR/multispectral image fusion for the detection of environmental hazards with a GIS. In Proceedings of SPIE - The International Society for Optical Engineering, 2014, https://doi.org/10.1117/12.2066476

[12] Lega, M., Casazza, M., Teta R. \& Zappa C.J., Environmental impact assessment: a multi-parametric approach for monitoring polluted coastal waters. International Journal of Sustainable Development and Planning, In press.

[13] Ferrara, C., Lega, M., Fusco, G., Bishop, P. \& Endreny, T., Characterization of terrestrial discharges into coastal waters with thermal imagery from a hierarchical monitoring program. Water, 9(7), p. 500, 2017. https://doi.org/10.3390/w9070500

[14] Gargiulo, F., Persechino, G., Lega, M. \& Errico, A., IDES project: a new effective tool for safety and security in the environment. International Conference on Algorithms and Architectures for Parallel Processing. Springer, Cham, pp. 201-208, 2013.

[15] Errico, A., Angelino, C.V., Cicala, L., Persechino, G., Ferrara, C., Lega, M., Vallario, A., Parente, C., Masi, G., Gaetano, R., Scarpa, G., Amitrano, D., Giuseppe Ruello, G., 
Verdoliva, L. \& Poggi, G., Detection of environmental hazards through the feature-based fusion of optical and SAR data: a case study in southern Italy. International Journal of Remote Sensing, 36(13), pp. 3345-3367, 2015. https://doi.org/10.1080/01431161.2015.1054960

[16] Mangoni, O., Imperatore, C., Tomas, C.R., Costantino, V., Saggiomo, V. \& Mangoni, A., The new carotenoid pigment moraxanthin is associated with toxic microalgae. Marine Drugs, 9(2), pp. 242-255, 2011. https://doi.org/10.3390/md9020242

[17] Casazza, M., Maraga, F., Liu, G., Lega, M., Turconi, L. \& Ulgiati, S., River water quality and its relation with air quality: a long-term case study in a remote and pristine NW Italian headwater catchment. Journal of Environmental Accounting and Management, 5(1), pp. 35-47, 2017. https://doi.org/10.5890/jeam.2017.03.004

[18] Casazza, M., Lega, M., Liu, G., Ulgiati, S. \& Endreny, T.A., Aerosol pollution, including eroded soils, intensifies cloud growth, precipitation, and soil erosion: a review. Journal of Cleaner Production, 189, pp. 135-144, 2018. https://doi.org/10.1016/j.jclepro.2018.04.004 